\title{
Bauman, Zygmunt, Michael Hviid Jacobsen y Keith Tester. 2019. ¿Para qué sirve realmente...? Un sociólogo. Ciudad de México: Paidós
}

Gabriela Grajales García ${ }^{1}$ ygmunt Bauman (1925 - 2017), fue un sociólogo y filósofo nacido en Pozman, Polonia en 1925; después que su familia huyó durante la Segunda Guerra Mundial, regresó a Polonia en donde laboró como docente de Sociología y Filosofía de la Universidad de Varsovia, posteriormente se refugió en Gran Bretaña en donde fue nombrado catedrático emérito de Sociología en la Universidad de Leeds. Tras su muerte, en 2017, diversos textos de Bauman fueron leídos y releídos, entre ellos ¿Para qué sirve realmente...? Un sociólogo, en el cual se hace referencia a la importancia de la Sociología en el mundo contemporáneo, así como del sociólogo como actor fundamental para el análisis de contextos sociales. El libro se encuentra dividido en los siguientes apartados: a) Prefacio, b) Introducción, 1) ¿Qué es la Sociología?, 2) ¿Por qué ser sociólogo?, 3) ¿Cómo hacer Sociología? y 4) ¿Qué puede conseguir la Sociología?

El prefacio, realizado por Michel Hviid Jacobsen y Keith Tester, es muy claro al mencionar que el libro intenta motivar a los sociólogos a ser sujetos activos para la recomposición del mundo en lugar de ser técnicos carentes de valores. Los diversos apartados del libro se encuentran constituidos por una serie de entrevistas a Bauman entre los años 2012-2013, no obstante, estas fueron organizadas por temáticas, sin perder la esencia de las entrevistas realizadas al autor. El objetivo del libro es crear consciencia al sociólogo para fomentar reflexiones sobre el mensaje moral y político de Zygmunt Bauman.

La introducción, también realizada por Michel Hviid Jacobsen y Keith Tester, hace referencia al concepto de imaginación sociológica propuesto por C. Wright Mills (2014), en el que sugiere que esta se relaciona directamente con la experiencia humana para dar cuenta de la realidad que se está viviendo en la sociedad; por lo tanto, la Sociología es altamente pertinente para el actual proceso de incertidumbre a

1- Nacionalidad: Mexicana. Grado: Doctorado . Especialización: Estudios Regionales. Adscripción: Universidad Autónoma de Chiapas. Correo electrónico: gabriela.grajales@unach.mx. ORCID: https://orcid.org/0000-0002-5090-9146 
nivel mundial. Sin embargo, Bauman menciona que la Sociología carece del reconocimiento como parte fundamental del mundo social, es por ello que urge un rescate de dicha ciencia ya que esto se sabía desde finales de los años 50, cuando Mills separó la imaginación sociológica de la Sociología, mostrando que estas no tienen relación, puesto que la primera se deriva de la experiencia del sociólogo -cualidad de mente- para comprender lo que sucede, mientras que la segunda solo puede ser considerada como aporte de información sobre un lugar o fenómeno determinado. La imaginación sociológica es por excelencia la esencia del sociólogo, quien a través de la vida personal se puede conectar con acontecimientos históricos y procesos sociales estructurales, cuando el sociólogo logre realizar dichas conexiones, entonces y solo entonces, la Sociología será útil y exitosa.

El capítulo uno se titula ¿Qué es la Sociología?, en este el autor menciona que su definición de Sociología corresponde a una conversación con la experiencia humana. Es sobre esta definición que Bauman realiza una importante distinción, pues menciona que el concepto de experiencia (experience) de los anglófonos es lo que más se aproxima a Erfahrungen y Erlebnisse que son conceptos derivados de los germanófonos, el primero significa "lo que me ocurre cuando interactúo con el mundo" y el segundo "lo que experimento", es por ello que su percepción de la Sociología es el conjunto de estos dos conceptos: Erfahrungen es la información sobre el mundo que es externo al sujeto mientras que Erlebnisse sucede dentro del sujeto a través de sus pensamientos y emociones; es por ello que el autor sugiere que existe un diálogo continuo entre Sociología y experiencia humana, por lo tanto se trata de emitir mensajes de manera constante sobre lo que sucede en el mundo, se puede decir que ambos conceptos son la dialéctica sobre la que funciona la Sociología.

En la entrevista del capítulo uno surge la pregunta sobre cuál es la relación entre política y Sociología, a lo que Bauman responde de manera muy precisa que por la misma naturaleza de ambas se encuentran estrechamente unidas, ya que la Sociología (considerando la dialéctica entre Erfahrungen y Erlebnisse) tiene la convicción de mostrar la objetividad engañosa de la política, sugiere que es problable que a través de la Sociología se pueda obtener una voz distinta a la institucionalizada, probablemente desde una visión de orden weberiano (Weber, 2014). Por ello, Bauman en reiteradas ocasiones menciona que en la mayor parte de textos sociológicos, al ser el inglés la lengua predilecta para escribir, se pierden los significados que se desean plasmar, por lo tanto puede haber problemas con la comprensión (sobre todo las subjetividades).

El capítulo uno, es esencial para articular las ideas que vienen después, por esa razón Bauman sugiere que se deben utilizar métodos científicos para encontrar la verdad o refutar la no verdad, es por ello que uno de los conceptos nodales del texto es que a través de la ciencia se puede establecer la relación dicotómica cartesiana entre sujeto y objeto, es decir, se tendrá una validación científica si lo que se somete como verdad cumple con los estándares científicos de un área determinada, no obstante, en las ciencias humanas, es indispensable que el objeto de estudio sea despojado de subjetividad, aunque Bauman establece que esto es totalmente perturbador porque la verdad-científica de las ciencias sociales se basa precisamente en la subjetividad humana. Tomando en consideración este último punto, puede establecerse que la Sociología es una disciplina crítica, no en términos de una gran teoría crítica, sino que existe un cúmulo de teorías que critican la realidad social cada vez que un científico social da cuenta de lo que sucede en un espacio-tiempo determinado.

El capítulo dos titulado ¿Por qué ser sociólogo? es sumamente interesante, debido a que después de haber definido qué es la Sociología, Bauman es cuestionado acerca de por qué decidió ser sociólogo y su 
motivación para continuar escribiendo, a lo que responde que primero él quería enfocarse en una carrera que explicara el funcionamiento del universo, sin embargo, después de ver la situación que vivía su natal Polonia, tomó la decisión de elegir una carrera que le permitiera dar cuenta de las realidades sociales derivadas de la miseria humana, es por ello que eligió ser sociólogo, lo cual para él es la única forma que tiene para vivir, dado que no puede ver el mundo con ojos diferentes.

Bauman sugiere que el sociólogo es esencial para la sociedad, porque una vez que aprende cómo hacer ciencia social durante su estancia en aulas universitarias se atreve a tomar otros caminos, esto último tiene estrecha relación con el concepto de imaginación sociológica del capítulo uno, ya que en la academia se obtienen las herramientas necesarias para el quehacer sociológico, sin embargo, es en la realidad social, fuera de las aulas, donde la imaginación sociológica se manifiesta, ejemplo de ello son Karl Marx, Georg Simmel y Max Weber.

Ahora bien, parte fundamental de la vida del sociólogo es la escritura, cuando a Bauman le preguntan sobre el público al que dirige sus textos, él plantea que los científicos sociales como Marx, Lenin, Adorno, Benjamin, Gramsci, Lukács o Althuser -e incluso el mismo Bauman-, fueron inspirados por otros científicos sociales y también ellos, en su momento, son fuente de inspiración y si bien en ocasiones escriben para un público determinado, lo cierto es que muchas veces las obras son leídas por personas que no fueron el público inicial; es más, Bauman menciona que sus escritos son textos en una botella, dejados en el mar, esperando algún destinatario; él los llama "misiles inteligentes", los cuales son seleccionados por diversos marineros.

A propósito de la elección de los textos, Bauman establece que parte fundamental de sus textos es la hermenéutica sociológica, la cual se enfoca en la interpretación de las decisiones humanas para responder problemas, desafíos o fenómenos en la sociedad, además de saber plantear diversas soluciones. Por tal motivo, debe dejarse a un lado que la Sociología es una ciencia que predice y verla como una ciencia que explica de manera profunda los acontecimientos sociales; por lo tanto, la hermenéutica sociológica se esfuerza en comprender las realidades humanas con herramientas que la propia ciencia proporciona.

Una de las preguntas clave del capítulo dos es sobre por qué los estudiantes de Sociología ya no leen a un cúmulo de sociólogos, sino que solo se enfocan en algunos cuantos; por ejemplo, se especializan en Bourdieu, Habermas, Luhmann o Bauman, ante ello el autor menciona que eso no es un problema de la Sociología sino de un patrón de cualquier rama del conocimiento, él menciona que en su juventud las ideas se encontraban agrupadas en escuelas, por lo tanto las ideas se leían en bloque, no obstante, si el estudiante se identificaba con un autor, simplemente lo buscaba de forma individual, cuestión que hoy se ve acelerada por el acceso a la información a través de la tecnología.

El capítulo dos concluye con la siguiente pregunta: ¿puede la Sociología hacer feliz a la gente? A esto Bauman responde que es una de las preguntas más difíciles de responder y que para hacerlo se basa en Johann Wolfgang Goethe, quien mencionaba que sí tuvo una vida feliz, aunque no podía recordar una sola semana de su vida siendo totalmente feliz.

El capítulo tres, que lleva por nombre: ¿Cómo hacer Sociología?, se enfoca en que el quehacer sociológico se basa en la observación minuciosa de la conducta humana, sobre todo porque ha habido una decadencia de los valores; por lo tanto, la Sociología tiene la tarea de hacer factible y plausible el hecho de elegir un valor. Es importante mencionar que esta no es quien dicta qué o cuáles valores se deben elegir, sino que el mismo actor social es quien define el conjunto de valores que servirán para mejorar la calidad 
de vida. Uno de los pasajes más importantes de este capítulo es la consideración de la obra de Bauman (2011) Daños colaterales. Desigualdades sociales en la era global, en donde se presentan fundamentos para que la Sociología tenga legitimidad científica; en este texto se aborda su historia, la cual se ha inclinado en los últimos tiempos hacia una mentalidad tecnológica, es decir, una cosificación del mundo social. Ante ello, los entrevistadores cuestionan a Bauman sobre si la Sociología debería ser solamente un diálogo crítico basado en la experiencia, a lo que el autor responde que probablemente en algunos casos del ámbito académico se acoja una Sociología poco crítica, una Sociología que sea útil al negocio viable. No obstante, a pesar que en el libro Daños colaterales se hable sobre la historia de la Sociología, Bauman es muy claro al sugerir que en realidad el libro se enfoca en los daños colaterales de la desigualdad en el mundo, es por ello que él sugiere que a través de la Sociología se utilicen estrategias como el diálogo continuo con la doxa, ya que las consecuencias de olvidar dicho diálogo, da como resultado que haya quienes sugieran que la Sociología hoy en día es irrelevante.

Otro de los puntos principales del capítulo tres radica en que una de las mejores formas para dar a conocer las ideas es a través de la escritura, es por ello que cuestionan a Bauman acerca de su forma de escribir, debido a que tiene predilección por los ensayos y las metáforas; el autor responde que el uso de metáforas es esencial para dar a conocer una idea, sobre todo porque estas han estado ahí desde los griegos, lo cual muestra que son altamente eficaces para que la idea sea transmitida de forma clara y eficiente; además, Bauman menciona que es una forma personal de plasmar sus pensamientos, por tal motivo, él exhorta a los sociólogos a escribir de la forma que más comodidad les represente. Basados en el proceso escritor, los entrevistadores preguntan a Bauman sobre el camino que debe tomar la Sociología actualmente, considerando que nos encontramos en un mundo más visual; ante ello el autor menciona que hoy en día tenemos más imágenes y menos palabras (incluso los jóvenes de hoy pueden comunicarse con monosílabos), no obstante, la Sociología por su naturaleza hermenéutica se encuentra atada a la palabra y por tanto a la escritura, puesto que la imaginación sociológica necesariamente debe tener palabras que estimulen al sociólogo y al lector no solo para comprender los textos, sino para mostrar lo que sucede en la realidad social, es por ello que las imágenes son bienvenidas siempre y cuando haya un rico contenido de letras. El final del capítulo tres hace alusión que en el caso de Bauman, puede reflejarse en sus textos la nostalgia del reflejo de la modernidad y posmodernidad ante la imagen del pasado, que hasta cierto punto tenían menos incertidumbre ante el actual contexto del consumismo y el materialismo.

El capítulo cuatro, titulado ¿Qué puede conseguir la Sociología?, es la parte final del libro en la cual puede notarse que brinda al lector el cierre deseado, ya que nuevamente cuestionan a Bauman acerca de para qué sirve la Sociología, a lo que él responde que esta sirve o debería servir para resolver problemas vitales, así también recalca la idea que esta debe ser tomada en serio, con compromiso y conciencia, dado que como mencionaba Thomas S. Kuhn, el pensamiento no es lineal, por lo tanto existe un largo camino por recorrer científicamente, por ello sugiere a los sociólogos que la Sociología no es una carrera para estar tranquilos o volverse ricos, al contrario, es un estilo de vida que conlleva un enorme trabajo y responsabilidad para dar cuenta de los sucesos en el mundo y entonces este sea un lugar mejor o, al menos, no sea peor. Derivado de ello, el sociólogo debe ser una persona honesta y ética, Bauman sugiere que debe tomarse en cuenta lo que Marx alguna vez planteó, al mencionar que los sociólogos pueden hacer historia pero no pueden elegir las condiciones en las que hacen su historia, por ello es necesario asumir el rol del sociólogo en el mundo, que además de ser esencial es altamente pertinente para la vida social 
contemporánea. Por lo tanto, se debe estar en contacto con lo que la sociedad ve, ejemplo de ello puede ser echar un vistazo a lo que hay en la radio o la televisión, de esta forma el sociólogo puede adentrarse al contexto social y obtener ideas para mejorar la calidad de vida, entonces estará logrando el objetivo de la imaginación sociológica de la que hablaba C. Wright Mills y que fue el punto de partida de este libro denominado ¿Para qué sirve realmente...? Un sociólogo.

Finalmente, se puede decir que el libro maneja un lenguaje sencillo, no obstante, es importante considerar que va dirigido a un público especializado en Sociología o áreas afines, ya que los conceptos que se utilizan son derivados de otras obras y autores de las ciencias sociales. En términos generales, este libro es un gran aporte para los sociólogos, puesto que se hace una reflexión acerca de la importancia de dar cuenta de los problemas que aquejan a la sociedad contemporánea, además de invitarlos a contribuir con propuestas para mejorar el mundo; por ello, desde el inicio de la obra hasta su culminación, la imaginación sociológica es el hilo conductor de las respuestas de Bauman durante las entrevistas. Por otro lado, se puede mencionar que los tópicos fueron clasificados de forma muy precisa, es por ello que el libro puede leerse de principio a fin o seleccionando los capítulos que se desean leer, de cualquer manera, todos los extractos de las entrevistas son una invitación al quehacer sociológico y a la constante reflexión social.

\section{Referencias}

Bauman, Zygmunt. 2011. Daños colaterales. Desigualdades sociales en la era global. Ciudad de México: FCE. Bauman, Zygmunt, Michael Hviid Jacobsen y Keith Tester. 2019. ¿Para qué sirve realmente...? Un sociólogo. Ciudad de México: Paidós.

Mills, Charles-Wright. 2014. La imaginación sociológica. Ciudad de México: FCE.

Weber, Max. 2014. Economía y sociedad. Ciudad de México: FCE. 